\title{
Estimation of forest biomass components using airborne LiDAR and multispectral sensors
}

\author{
Ana Hernando (1), \\ Luis Puerto( ${ }^{(2)}$, \\ Blas Mola-Yudego ${ }^{(2)}$, \\ José Antonio Manzanera (1), \\ Antonio García-Abril (1), \\ Matti Maltamo (2), \\ Rubén Valbuena ${ }^{(3-4)}$
}

\begin{abstract}
In order to consider forest biomass as a real alternative for energy production, it is critical to obtain accurate estimates of its availability using non-destructive sampling methods. In this study, we estimate the biomass available in a Scots pine-dominated forest (Pinus sylvestris L.) located in Spain. The biomass estimates were obtained using LiDAR data combined with a multispectral camera and allometric equations. The method used to fuse the data was based on back projection, which assures a perfect match between both datasets. The results present estimates for each of the seven different biomass components: above ground, below ground, log, needles, and large, medium and small branches. The accuracy of the models varied between $R^{2}$ values of 0.46 and 0.67 with RMSE\% ranging from $15.72 \%$ to $35.43 \%$ with all component estimates below $20 \%$, except for the model estimating biomass of big branches. The models in this study are suitable for the estimation of biomass and demonstrate that computation is possible at a fine scale for the different biomass components. These remote sensing methods are sufficiently accurate to develop biomass resource cartography for multiple energy uses.
\end{abstract}

Keywords: Biomass Components, Forest Inventory, Airborne Laser Scanning, Multispectral Imagery, Data Fusion, Nearest Neighbor
2017). These forest components (branches, treetops, needles and even stumps and roots) are generated through forest management, and they are not usually removed from the stand because of their small diameters.

Many forest inventories currently focus mainly on timber volume for forest industries and they usually lack the quality characteristics demanded by regional managers and renewable biomass energy industry (Riaño et al. 2004, García et al. 2010, Hauglin et al. 2013). Some of those characteristics are the stock of detailed tree biomass components and the spatial location of these resources at finer scales (Montero et al. 2005, Mauro et al. 2016). In this sense, the contributions of remote sensing estimates are becoming a valuable tool (Hernando et al. 2012, Anderson \& Mitchell
(1) Universidad Politécnica de Madrid, E.T.S.I. Montes, Research Group SILVANET, Ciudad Universitaria, 28040 Madrid (Spain); (2) University of Eastern Finland, School of Forest Sciences, P.O. Box 111, Fl80101, Joensuu (Finland); (3) University of Cambridge, Department of Plant Sciences, Forest Ecology and Conservation, Downing Street, CB2 3EA Cambridge (UK); (4) Bangor University, School of Natural Sciences, Thoday building, LL57 2UW Bangor (UK)

@ Ana Hernando (ana.hernando@upm.es)

Received: Jan 22, 2018 - Accepted: Feb 06, 2019

Citation: Hernando A, Puerto L, Mola-Yudego B, Manzanera JA, García-Abril A, Maltamo M, Valbuena R (2019). Estimation of forest biomass components using airborne LiDAR and multispectral sensors. iForest 12: 207-213. - doi: 10.3832/ifor2735-012 [online 2019-04-25]

Communicated by: Davide Travaglini
2016) to produce accurate and cost-competitive estimates at the landscape level (Zolkos et al. 2013). However, there are some limitations for certain remote sensing techniques, such as satellite-borne optical sensors or synthetic aperture radar, that have shown signal saturation in forest environments with very high biomass density (Cohen \& Spies 1992). The use of LiDAR sensors on-board airplanes, known as airborne laser scanning, has proved to be the best option for biomass accounting, applied separately or in combination with other active or passive sensors (Bright et al. 2012, Zolkos et al. 2013). Previous studies have shown the reliability of LiDAR to obtain estimates of above-ground biomass (Patenaude et al. 2004), below-ground biomass (Naesset 2004, Kristensen et al. 2015), and of other biomass components (Riaño et al. 2004, García et al. 2010, Hauglin et al. 2013). Additional studies have also investigated techniques for fusion of images from airborne or satellite-borne multispectral (MS) sensors for the purpose of biomass assessment (Popescu et al. 2004).

Forest inventories lack information on tree biomass components and the precise spatial location of these resources at finer scales (Gómez et al. 2010). Current methods of spatial biomass assessment based on national forest inventories present limitations such as the lack of accuracy for efficient spatial planning, among others ( $\mathrm{Pa}$ nichelli \& Gnansounou 2008). Many predictions of forest-based biomass have therefore been restricted to a regional scale, or 


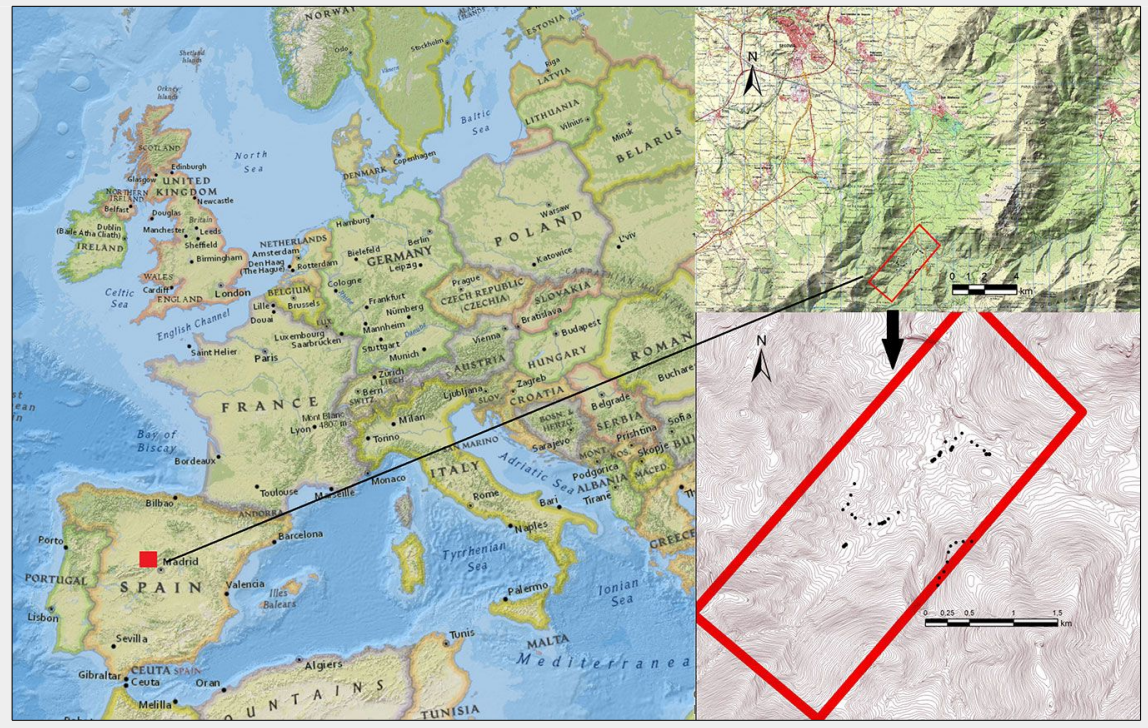

Fig. 1 - Study area location (red rectangular frame) and field plot distribution (black dots).

have been spatially interpolated (LópezRodríguez et al. 2009). Furthermore, thinning and other partial treatments are widely used to reduce fire risk, remove non-native and invasive species, and restore forests to historic reference conditions, often at high net cost (Anderson \& Mitchell 2016). In most cases, this forest waste generated by thinning and clearing is not used for any purpose, because it is not included in current inventories.

In the present study, we introduce a novel framework for predicting biomass based on the combination of airborne LiDAR and multispectral cameras, using advanced techniques of sensor fusion and non-parametric imputation (Brosofske et al. 2014, Chirici et al. 2016) that minimize noise and loss of information.

\section{Material and methods}

\section{Study area and field information}

The studied area (Fig. 1) was a Scots pinedominated (Pinus sylvestris L.) forest in Valsaín (Spain; approx. coordinates: $41^{\circ} 44^{\prime} \mathrm{N}$, $04^{\circ} 39^{\prime} \mathrm{W}$; elevation $1300-1500 \mathrm{~m}$ a.s.l.). The ground data included 37 plots; each plot entailed two concentric circles with radii of
$10 \mathrm{~m}$ and $20 \mathrm{~m}$, respectively (Valbuena et al. 2013). In the inner circle, all trees were measured, including seedlings and saplings, whereas in the outer circle only trees with diameter at breast height $(\mathrm{dbh}, \mathrm{cm})$ over $10 \mathrm{~cm}$ were measured. Corroborating within-plot homogeneity in the field, information sampled within the inner plot was expanded to the outer plot (Valbuena et al. 2013). Tree top height $(h, m)$ was determined with a Vertex III Hypsometer (Haglof, Sweden). Plot centers were staked out using a HiPer-Pro ${ }^{\circledR}$ (Topcon, California) receiver set at 1-2 $\mathrm{m}$ above the ground for differentially-corrected global navigation satellite systems (GNSS) positioning (Valbuena et al. 2010). Mean stand density ( \pm standard deviation) of the study area was $732.3 \pm 559.2$ stems ha-1, mean basal area was $41.8 \pm 11.2 \mathrm{~m}^{2}$ ha ${ }^{-1}$ and mean standing volume was $390.7 \pm 258.6 \mathrm{~m}^{3} \mathrm{ha}^{-1}$. Locallyadjusted tree allometry specific for $P$. sylvestris was employed to derive the dryweight biomass components (Montero et al. 2005). Equations were used for aboveground biomass ( $a g b, \mathrm{~kg})$, root biomass (below-ground biomass: bgb, kg), log biomass ( $\mathrm{lb}, \mathrm{kg}$ ), needle biomass ( $\mathrm{nb}, \mathrm{kg})$, and branch biomass ( $b b)$ with diameter $\varnothing>$

Tab. 1 - Summary of field plot reference data (Mean; Standard deviation, SD; Maximum, Max; Minimum, Min; Coefficient of Variation, CV) of the different observed biomass components.

\begin{tabular}{lrrrrr}
\hline Components in Mg ha $^{-1}$ & Mean & SD & Max & Min & CV \\
\hline Above-ground biomass $(A G B)$ & 211.313 & 58.140 & 318.798 & 106.474 & 0.275 \\
Below-ground biomass $(B G B)$ & 61.140 & 18.426 & 94.528 & 27.623 & 0.301 \\
Log biomass $(L B)$ & 175.830 & 54.707 & 274.803 & 76.653 & 0.311 \\
Needle biomass (NB) & 10.544 & 2.885 & 17.212 & 4.615 & 0.274 \\
Big-branch biomass (bBB) & 8.959 & 4.561 & 19.761 & 1.416 & 0.509 \\
Medium-branch biomass (mBB) & 18.763 & 4.630 & 27.878 & 9.286 & 0.247 \\
Small-branch biomass $(s B B)$ & 13.977 & 3.824 & 22.816 & 6.118 & 0.274 \\
\hline
\end{tabular}

$7 \mathrm{~cm}$ (big-branch biomass: bbb, kg), $2>\varnothing>$ $7 \mathrm{~cm}$ (medium-branch biomass: $\mathrm{mbb}, \mathrm{kg}$ ) and $\varnothing<2 \mathrm{~cm}$ (small-branch biomass: sbb, $\mathrm{kg}$ ), following (eqn. 1-7):

$$
\begin{aligned}
& a g b=0.08439 \cdot d b h^{2.41194} \\
& b g b=0.01089 \cdot d b h^{2.62841} \\
& l b=0.0232141 \cdot d b h^{2.70808} \\
& n b=0.108085 \cdot d b h^{1.50099} \\
& b b b=3.6999 \cdot 10^{-7} \cdot d b h^{4.80367} \\
& m b b=0.02036 \cdot d b h^{2.1408} \\
& s b b=0.14323 \cdot d b h^{1.51001}
\end{aligned}
$$

The forest stand attributes and characteristics were calculated by aggregating the tree-level biomass estimates (in lower-case letters, $\mathrm{kg}$ ) into per-hectare totals at the plot-level (capital letters, $\mathrm{Mg} \mathrm{ha}^{-1}$ ). The biomass components were organized into three hierarchical groups: the first group showed components of total biomass, above-ground biomass ( $\left.A G B, M g h^{-1}\right)$ and below-ground biomass ( $\mathrm{BGB}, \mathrm{Mg} \mathrm{ha}^{-1}$ ), obtained as aggregations of the values calculated with eqn. 1 and eqn. 2, respectively. The second group disaggregated $A G B$ into several components: log biomass ( $L B, M g$ $\left.h^{-1}\right)$, needle biomass ( $\left.N B, M g a^{-1}\right)$ and branch biomass (BB, Mg ha ${ }^{-1}$ ). LB and NB were obtained using eqn. 3 and eqn. 4 , respectively, whereas BB was calculated as aggregation of eqn. 5 , eqn.6, and eqn. 7 separated into components, namely: big (bBB, Mg ha ${ }^{-1}$ ), medium ( $\mathrm{mBB}, \mathrm{Mg} \mathrm{ha}^{-1}$ ) and small (sBB, Mg ha-1) branch biomass. Biomass components of the study area, derived from the sample plots, are given in Tab. 1.

\section{Remote sensing datasets and back- projecting sensor fusion}

Active LiDAR and passive MS sensors were installed together on a gyro-stabilized platform on-board a 404-Titan ${ }^{\text {TM }}$ (Cessna, Kansas, USA) with double photogrammetric window, in-flight GNSS and inertial navigation systems (INS). These provided the position and attitude of each sensor, which were used as external orientation in the sensor fusion procedure (Valbuena et al. 2011) as described below. The LiDAR sensor consisted of an airborne laser scanner ALS50-II ${ }^{\circledast}$ (Leica Geosystems, Switzerland) operating at a pulse frequency of 55 $\mathrm{kHz}$. A maximum of four separate discrete returns were obtained from an approximate pulse footprint diameter of $0.5 \mathrm{~m}$ at nadir (Baltsavias 1999). The flight took an approximate height of $1500 \mathrm{~m}$ and ground speed of $72 \mathrm{~m} \mathrm{~s}^{-1}$. These flight parameters yielded a nominal average pulse density of 1.15 pulses $\mathrm{m}^{-2}$ (Baltsavias 1999). An approximate total area of 800 ha was covered by four scan lines with a swath width of $665 \mathrm{~m}$ and a $40 \%$ side lap. Returns were classified 
as ground using a lowest elevation of $2 \mathrm{~m}$ and threshold angle of $12-75^{\circ}$ in Terrascan ${ }^{\circledR}$ (Terrasolid, Finland). Ground returns were interpolated into a digital terrain model (DTM) at a spatial resolution of $1 \mathrm{~m}$. Based on ground surveying quality control, its precision was calculated to be approximately $15 \mathrm{~cm}$. The DTM values were subtracted from each individual return, obtaining their heights above ground $(\mathrm{H}, \mathrm{m})$.

The MS sensor consisted of a digital mapping camera $\left(\mathrm{DMC}^{\oplus}\right.$, Zeiss-Intergraph, Germany) system composed of four chargecoupled device (CCD) heads preceded by filters providing selective sensitivity for red, green, blue and near-infrared (NIR). These were the original bands of narrower spectral resolution and coarser spatial resolution (in comparison with the radiometric information registered by the panchromatic lens system) which was dismissed from this study in order to maintain the integrity of the irradiance recorded for the narrow bands. Digital numbers obtained with a 12-bit radiometric resolution from the spectral bands for red and NIR were employed to obtain (non-orthorectified) images containing NDVI values calculated at pixel-level.

These images had an approximate ground sampling distance of $60 \mathrm{~cm}$, as can be deduced from the given flight height and the focal length of $f=30 \mathrm{~mm}$ of these MS heads. The lenses of the matricial array frame of the described DMC system, however, direct the light to a matrix of CCD sensors with a central projection. Due to this perspective, equal segments within the NDVI image represent different distances on the ground, depending whether they are at nadir or close to the edge of the image. As an airborne sensor, while the low flying altitude yielded high spatial resolutions, it also presented the shortcoming that anisotropy and within-picture scale differences according to nadir angles are larger than when using a satellite-borne sensor. For these reasons, we chose to fuse sensor data using a projection procedure, since this assured the correspondence between the $H$ and NDVI information (Valbuena et al. 2011). The procedure consisted of projecting each first return from the LiDAR dataset into the most nadiral NDVI image available, retrieving the NDVI value of the pixel at that position, which effectively resulted in an NDVI-colored LiDAR point cloud. In order to model the central perspective of the MS sensor and render the positions of LiDAR returns on the ground onto the location of the CCD frame at the time of exposure, the three-dimensional geo-coordinates of each LiDAR re$\operatorname{turn}(X, Y, Z ; m)$ were projected into two-dimensional photo-coordinates $\left(X_{\mathrm{ph}}, Y_{\mathrm{ph}} ; \mathrm{mm}\right)$ according to the collinearity equations:

$$
\begin{aligned}
& \frac{X_{p p}-X_{p h}}{f}= \\
& \frac{m_{11}\left(X-X_{0}\right)+m_{12}\left(Y-Y_{0}\right)+m_{13}\left(Z-H_{0}\right)}{m_{31}\left(X-X_{0}\right)+m_{32}\left(Y-Y_{0}\right)+m_{33}\left(Z-H_{0}\right)}
\end{aligned}
$$
cients of $\boldsymbol{Y}$ and $\boldsymbol{X}$, respectively. Twenty combinations of both $H$ and NDVI metrics were selected based on the CCA results
$\frac{Y_{p p}-Y_{p h}}{f}=$

$\frac{m_{21}\left(X-X_{0}\right)+m_{22}\left(Y-Y_{0}\right)+m_{23}\left(Z-H_{0}\right)}{m_{31}\left(X-X_{0}\right)+m_{32}\left(Y-Y_{0}\right)+m_{33}\left(Z-H_{0}\right)}$

where the center of the NDVI image was given by the principal point $\left(X_{\mathrm{pp}}, Y_{\mathrm{pp}} ; \mathrm{mm}\right)$ obtained, and the position of the plane at the time of exposure $\left(X_{0}, Y_{0}, Z_{0} ; m\right)$ was given by the GNSS position of the platform obtained in-flight. Likewise, the INS provided information on the attitude of the CCD frame axes with respect to the coordinate system used as the plane's roll, pitch and yaw ( $\omega, \varphi, k ; \mathrm{rad})$, i.e., rotation angles around along-track, across-track and vertical axes from the sensor's platform, respectively. These angle parameters were used to define the rotation matrix $\boldsymbol{M}_{3 \mathrm{C}_{3}}=$ $\left(m_{11}, \ldots, m_{33}\right)$ that was applied to eqn. 8 and eqn. 9. The resulting root mean square error in co-registration of the LIDAR-MS fusion product was $0.54 \mathrm{~m}$, therefore mainly dependent on the spatial resolution of the MS image (Valbuena et al. 2011).

\section{Predictor computation and most similar neighbor imputation}

The colored ALS returns backscattered from the measured field plots were extracted, in order to calculate area-based predictor variables from them (Manzanera et al. 2016) using FUSION software (USDA Forest Service - McGaughey 2012). In addition to the traditional $\mathrm{H}$ metrics describing the distribution of ALS heights (Naesset 2002, Maltamo et al. 2014), we also calculated descriptors for the distribution of NDVI values, therefore obtaining NDVI metrics (henceforth indicated as either Hxxx or NDVI.xxx, where $x x x$ refers to each given metric). All of these metrics were used as a matrix of predictors including both $\mathrm{H}$ and NDVI metrics ( $\boldsymbol{X}_{\mathrm{H}+\mathrm{NDVI}}$ - Manzanera et al. 2016) for the MSN (Most Similar Neighbor) estimation (Moeur \& Stage 1995) of the biomass components $\boldsymbol{Y}=(A G B, B G B, L B$, $N B, B B, b B B, m B B, s B B$ ). These were done using the package "yalmpute" (Crookston \& Finley 2008) for $k$-NN imputation in the $R$ statistical environment (R Core Team 2011), which has already been demonstrated to be useful in predicting forest variables using LiDAR data (Chirici et al. 2016) and multispectral data (Mura et al. 2018). The feature space $\boldsymbol{X}$ was modified into projections obtained from a canonical correlation analysis (CCA), which compressed the original multidimensionality into a few components which maximized $\operatorname{cov}(\boldsymbol{X}, \boldsymbol{Y})$. Hence, these components were linear combinations of the response $(\boldsymbol{U})$ and predictors $(\boldsymbol{V})$ :

$$
\begin{aligned}
& \boldsymbol{U}=\alpha \cdot \boldsymbol{Y} \\
& \boldsymbol{V}=\gamma \cdot \boldsymbol{X}
\end{aligned}
$$

(Manzanera et al. 2016) and hypothesis tests (Valbuena et al. 2016), eliminating 


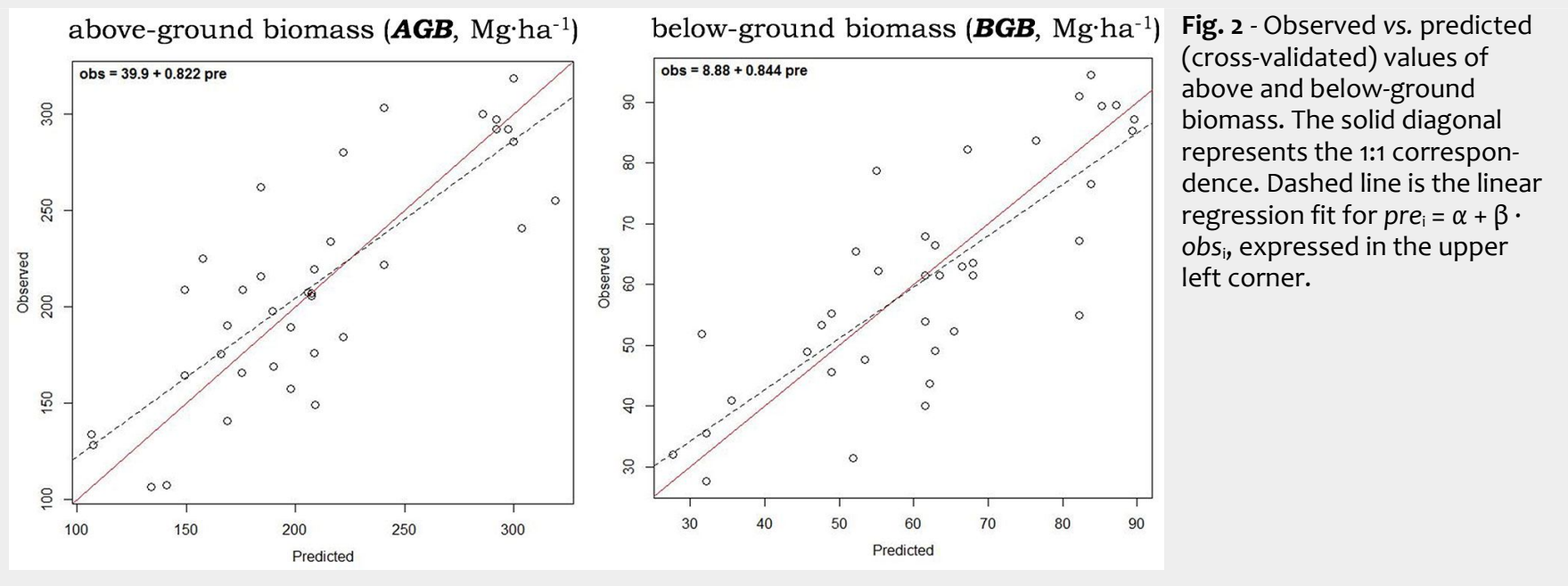

Tab. 2 - Summary diagnosis (bias, $M g$ ha ${ }^{-1}$; percentage of bias, \%; root mean square difference, RMSD, Mg ha' ${ }^{-1}$; percentage of RMSD, \%; coefficient of determination, $R^{2}$; index of agreement, $d$ ) of most similar neighbor (MSN) predictions for above and belowground fractions of total biomass.

\begin{tabular}{lcccccc}
\hline Biomass components & $\begin{array}{c}\text { bias } \\
\left(\mathrm{Mg} \mathrm{ha}^{-1}\right)\end{array}$ & $\begin{array}{c}\text { bias\% } \\
(\%)\end{array}$ & $\begin{array}{c}\text { RMSD } \\
\left(\mathrm{Mg} \mathrm{ha}^{-1}\right)\end{array}$ & $\begin{array}{c}\text { RMSD\% } \\
(\%)\end{array}$ & $\boldsymbol{R}^{2}$ & $\boldsymbol{d}$ \\
\hline $\begin{array}{l}\text { Above-ground biomass } \\
(A G B)\end{array}$ & -1.247 & -2.635 & 35.34 & 16.724 & 0.643 & 0.819 \\
$\begin{array}{l}\text { Below-ground biomass } \\
(B G B)\end{array}$ & 0.803 & 1.313 & 11.276 & 18.443 & 0.629 & 0.811 \\
\hline
\end{tabular}

Tab. 3 - Summary diagnosis (bias, $M g$ ha ${ }^{-1}$; percentage of bias, \%; root mean square difference, RMSD, Mg ha'; percentage of RMSD, \%; coefficient of determination, $R^{2}$; index of agreement, $d$ ) of most similar neighbor (MSN) predictions for separate fractions of above-ground biomass: log, needle and branch biomass.

\begin{tabular}{lcccccc}
\hline Biomass components & $\begin{array}{c}\text { bias } \\
\left(M^{-1} \mathrm{ha}^{-1}\right)\end{array}$ & $\begin{array}{c}\text { bias\% } \\
(\%)\end{array}$ & $\begin{array}{c}R M S D \\
\left(\mathrm{Mg} \mathrm{ha}^{-1}\right)\end{array}$ & $\begin{array}{c}R M S D \% \\
(\%)\end{array}$ & $R^{2}$ & $\boldsymbol{d}$ \\
\hline $\begin{array}{l}\text { Log biomass } \\
(L B)\end{array}$ & 4.683 & 2.664 & 32.599 & 18.54 & 0.668 & 0.843 \\
$\begin{array}{l}\text { Needle biomass } \\
(N B)\end{array}$ & 0.198 & 1.882 & 2.108 & 19.99 & 0.493 & 0.725 \\
$\begin{array}{l}\text { Branch biomass } \\
(B B)\end{array}$ & 0.654 & 1.708 & 6.967 & 18.205 & 0.462 & 0.736 \\
\hline
\end{tabular}

al. 2016), so that whenever these tests failed the model was rejected and the initial selection of predictors was further constrained (Valbuena et al. 2016).

\section{Results}

Above- and below-ground biomass

The hypothesis tests applied to the 1:1 fit of observed vs. predicted plots corresponding to above and below-ground biomass models were successful, obtaining unbiased predictions (obs $=39.9+0.822$. pre, and: obs $=8.88+0.844 \cdot$ pre, respectively - Fig. 2). The relative precision of the $\mathrm{AGB}$ and $\mathrm{BGB}$ estimates (RMSD\%) ranged from $16.72 \%$ to $18.44 \%$ respectively and the absolute precision of the estimates (RMSD) from $35.340 \mathrm{Mg} \mathrm{ha}^{-1}$ for above-ground biomass to $11.276 \mathrm{Mg}$ ha-1 for below-ground biomass (Tab. 2). They reached an index of agreement $(d)$ of $81.9 \%$ and $81.1 \%$ between observed and predicted, with $64.3 \%$ and $62.9 \%$ of explained variance $\left(R^{2}\right)$, respectively (Tab. 2).

Components of above-ground biomass The hypothesis tests applied to the 1:1 fit
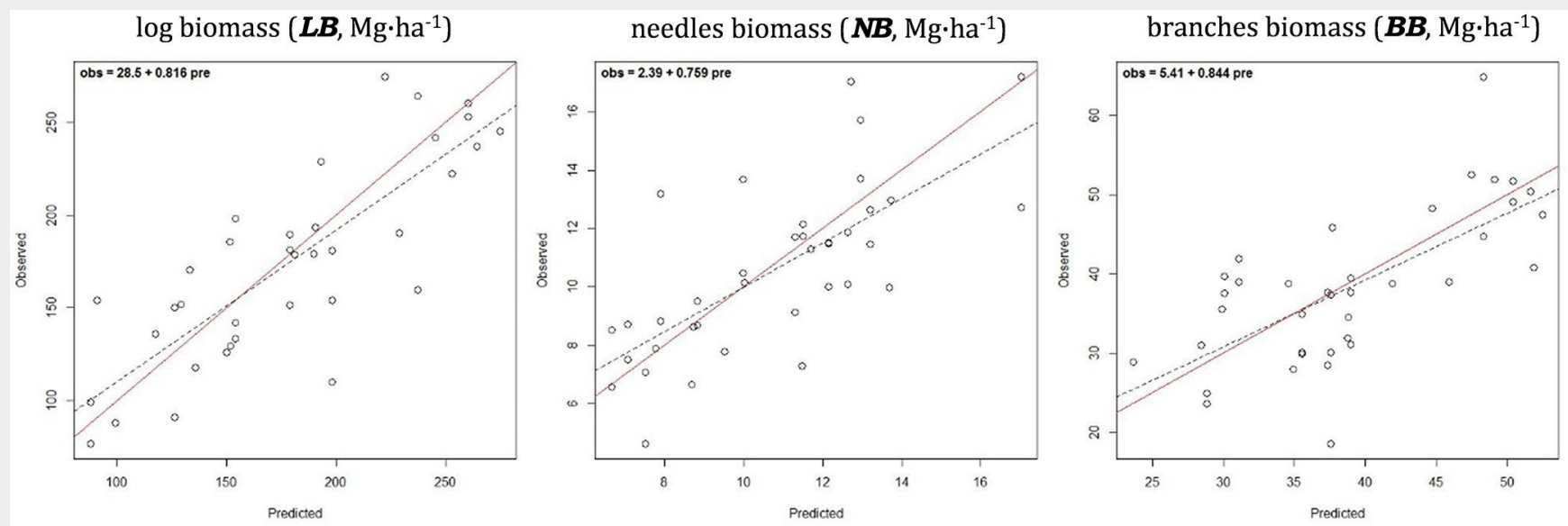

Fig. 3 - Observed vs. predicted (cross-validated) values for separate components of above-ground biomass: log, needle and branch biomass. The solid diagonal represents the 1:1 correspondence. Dashed line is the linear regression fit for pre $e_{\mathrm{i}}=\alpha+\beta \cdot \mathrm{obs}_{\mathrm{i}}$, expressed in the upper left corner. 

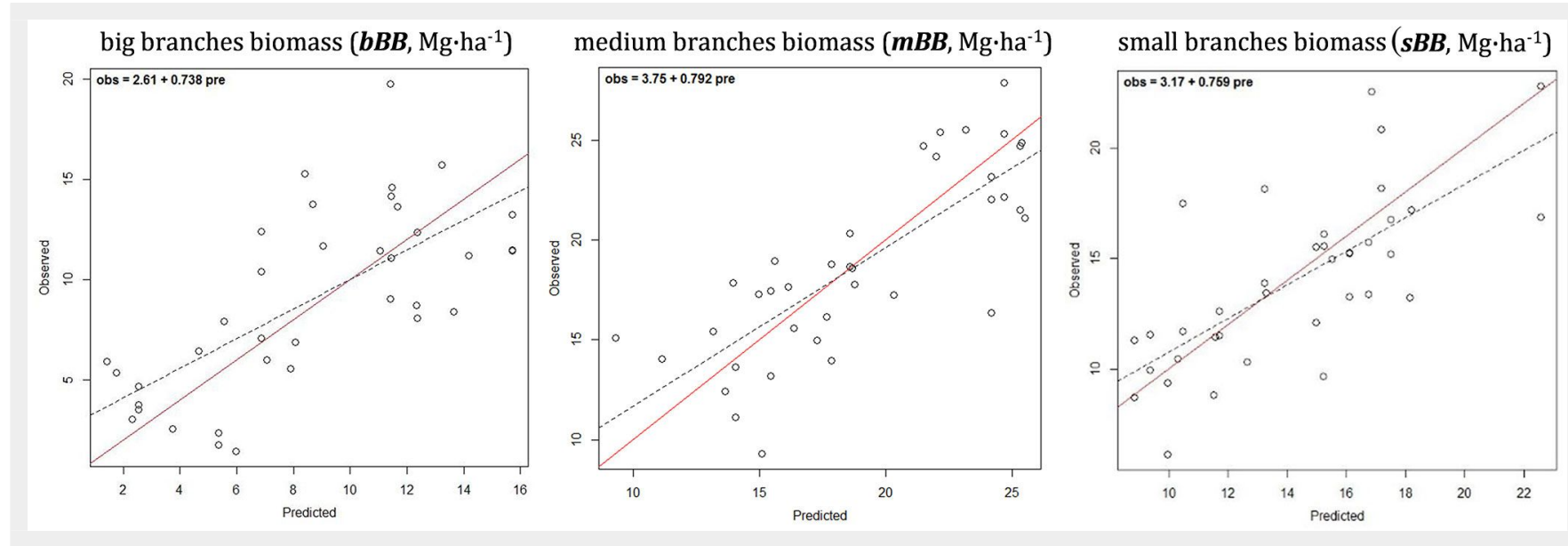

Fig. 4 - Observed vs. predicted (cross-validated) values of components of branch biomass separated by size. The solid diagonal represents the 1:1 correspondence. Dashed line is the linear regression fit for $\operatorname{pre}_{\mathrm{i}}=\alpha+\beta \cdot \mathrm{obs}_{\mathrm{i}}$, expressed in the upper left corner.

of observed vs. predicted plots corresponding to models for the separate components of the AGB predicting the biomass accumulated at the log, branch and needle levels, respectively $L B, B B$ and $N B$ also passed successfully, showing unbiased predictions (obs $=28.5+0.816 \cdot$ pre; obs $=2.39$ $+0.759 \cdot$ pre; and obs $=5.41+0.844 \cdot$ pre, respectively - Fig. 3). These models had a RMSD\% ranging between $18.21 \%$ and $19.99 \%$ (Tab. 3). They reached a $d$ ranging from $84.3 \%$ to $72.5 \%$ between observed and predicted, with $46.2 \%$ and $66.8 \%$ of explained variance. The highest $R^{2}$ values corresponded with the log biomass model and the lower with the model predicting biomass content for branches.

\section{Different-sized components of branch biomass}

The hypothesis tests applied to the 1: $1 \mathrm{fit}$ of observed vs. predicted plots corresponding to models predicting biomass for the different branch sizes (big, medium and small) also showed unbiased predictions (obs $=2.61+0.738 \cdot$ pre; obs $=3.75+$ $0.792 \cdot$ pre; and obs $=3.17+0.759 \cdot$ pre, respectively - Fig. 4). The model predicting biomass in big branches (bBB) had the biggest relative error $35.43 \%$ (Tab. 4). It is also worth to mention that in the particular case of the MSN estimation of biomass in big branches, $b B B$, the CCA-based preselection of variables with hypothesis test restriction showed no explanatory capacity for any of the NDVI metrics included. Regarding the other two branch size models: medium and small branches, their RMSD\% ranged $15.72-19.99 \%$ and the index of agreement reached $81.4 \%$, and the model predicting biomass for medium branches had the highest $R^{2}$.

\section{Discussion}

The present study assessed forest biomass components using a remote sensing technique that combines LiDAR metrics with NDVI computed from a multispectral camera, complementing previous research

Tab. 4 - Summary diagnosis (bias, $M g$ ha" ${ }^{-1}$; percentage of bias, \%; root mean square difference, RMSD, Mg ha'; ; percentage of RMSD, \%; coefficient of determination, $R^{2}$; index of agreement, $d$ ) of most similar neighbor (MSN) predictions for branch biomass fractions separated by size. Biomass in branches with diameter $>7 \mathrm{~cm}$ (big branches, $\mathrm{bBB}$ ), $2>$ diameter $>7 \mathrm{~cm}$ (medium branches, $\mathrm{mBB}$ ) and diameter $<2 \mathrm{~cm}$ (small branches, $\mathrm{SBB}$ ).

\begin{tabular}{lcccccc}
\hline Biomass components & $\begin{array}{c}\text { bias } \\
\left(M_{\mathrm{g} \mathrm{ha}} \mathbf{- 1}^{-1}\right)\end{array}$ & $\begin{array}{c}\text { bias\% } \\
(\%)\end{array}$ & $\begin{array}{c}\text { RMSD } \\
\left(\mathrm{Mg} \mathrm{ha}^{-1}\right)\end{array}$ & $\begin{array}{c}\text { RMSD\% } \\
(\%)\end{array}$ & $\boldsymbol{R}^{2}$ & $\boldsymbol{d}$ \\
\hline $\begin{array}{l}\text { Big-branch biomass } \\
(b B B)\end{array}$ & -0.158 & -1.768 & 3.174 & 35.432 & 0.545 & 0.701 \\
$\begin{array}{l}\text { Medium-branch biomass } \\
(m B B)\end{array}$ & 0.180 & 0.958 & 2.950 & 15.721 & 0.617 & 0.814 \\
$\begin{array}{l}\text { Small-branch biomass } \\
(s B B)\end{array}$ & 0.263 & 1.882 & 2.794 & 19.988 & 0.493 & 0.725 \\
\hline
\end{tabular}

on the estimation of forest biomass through the fusion of active and passive sensors (Ediriweera et al. 2014). The biomass assessment was carried out separately for the different forest biomass components in order to provide detailed information useful for bioenergy production purposes. The results were generated using allometric equations developed for the region and targeted at different species (Montero et al. 2005).

The added value of the results presented in this study lies in the improvements achieved in comparison to previous studies using similar or alternative methodologies. Previous biomass studies using airborne LiDAR have used indirect calculations by extracting the forest variable values from $\mathrm{Li}$ DAR data and then using them as an input in the biomass allometric equations (Kotamaa et al. 2010). Other studies have calculated biomass directly from LiDAR data but focusing only on above ground biomass (Naesset 2004, García et al. 2010) or on some of the components to estimate their contribution to carbon stocks (Montealegre-Gracia et al. 2017), but not for the whole tree with roots included. There is also an added value for the combination of LiDAR data with multispectral sensors (Straub \& Koch 2011), and in particular for the data fusion improvements implemented in this study (Valbuena et al. 2011), and the feasibility of the estimation method for the assessment of forest variables (Moeur \& Stage 1995, Packalén et al. 2009).

The assessment of separate components of above-ground biomass provides forest managers with greater flexibility in decision-making, since not all the components are considered for the same purpose, depending on wood quality and market prices (Solberg et al. 2014). Logs are usually the main product, and other parts like small branches and treetops are left on the ground for environmental reasons, but they can also be used for energy purposes, providing an added value (Asikainen et al. 2008). The estimation of all the above ground biomass components is therefore fundamental to correctly assess the energy potential of a certain area or region (Verkerk et al. 2011). On the other hand, foliage should not be included as biomass for energy, due to the ecologic role it plays in the nutrient cycle (Straub \& Koch 2011). The results obtained in this study showed that these remote sensing methods have great potential for reliably estimating belowground biomass, and not only aboveground biomass. Their estimation is there- 
fore more practical for ecological purposes (Montealegre-Gracia et al. 2017). Though the accuracy of our models was not as high as in other studies (García et al. 2010), we can still conclude that LiDAR is a suitable tool to assess branch biomass, and branch biomass is better assessed from the air than from field measurements (Hauglin et al. 2013). In the case of below-ground biomass components, these presented a higher predictive power taking into ac count that this component is retrieved by surrogating relations, and there is no direct relation with LiDAR returns or with the multispectral camera.

Previous studies have included treetop estimates as a part of the big-branch biomass estimates (Jenkins et al. 2003). In this study, it was not possible to consider this fact as a separate component due to the lack of available allometric equations considering tree tops as a separate part of the branches or stem. Treetops are a common logging waste, often used for energy purposes, and although they represent a smal percentage of the trees biomass, they can result in an average annual potential ca. 0.27 million $\mathrm{m}^{3}$ of biomass for energy. It would therefore be interesting to devote further studies to the development of specific allometric equations for this biomass component in particular. Although the use of allometric equations as reference values present limitations, they are considered the most available source for ground data, since it would be unfeasible to apply destructive sampling in every separate study (Hauglin et al. 2013). It would also be interesting to apply the same methodology in other forest stands with different charac teristics (species and ages) to develop a sensitive analysis observing how the biomass estimation changes under other conditions.

Estimates of available biomass resources should be accurate, especially when related to management decisions and planning of biomass supply (for new or existing energy plants), and previous studies have recommended a threshold of $20 \%$ requirement for RMSE\% when estimating biomass from LiDAR (Zolkos et al. 2013). Our results fulfill this recommended threshold in all the components except for big-branch biomass (bBB). A general comparison of our results with similar studies (García et al. 2010, González-Olabarria et al. 2012) demonstrates higher accuracy in our approach: lower error, better $R^{2}$ and better index of agreement. These improvements are related to the combined use of LiDAR and multispectral sensors (Manzanera et al. 2016) and the perfect match between both datasets achieved by the back-projecting data fusion method (Valbuena et al. 2011).

Considering these sensor-fusion techniques (combination of airborne LiDAR and multispectral camera) that minimize noise and loss of information, we recommend that future forest inventories include for- est biomass mapping for renewable biomass energy (Heiskanen et al. 2017). Further research could use this type of cartography to optimize transportation, which is the most expensive operational phase in this process (Kizha \& Han 2016), and evaluate derived trade-offs accounting for transportation costs as well (Gómez et al. 2010).

\section{Conclusions}

From our results, we can conclude that the combination of LiDAR and NDVI from a multispectral camera is a valid approach to estimate the different forest biomass components. The combined use of adequate allometric equations, back-projection data fusion and Most Similar Neighbor methods provided an estimate using the latest advances in the state-of-the-art of multisource assessment of biomass for bioenergy purposes. The methods adopted here represent a useful tool for applications of forest biomass availability and spatial distribution where more detailed information of the different components is required. It also demonstrates that computation can be done at a fine scale, for the different forest biomass components, and that it is sufficiently accurate to develop cartography for bioenergy resources management.

\section{Acknowledgments}

This work was partially supported by the Spanish Directorate General for Scientific and Technical Research under Grant CGL2013-46387-C2-2-R. We also thank the Valsain Forest Center, of the National Park Body (Spain), for their valuable help. Ruben Valbuena's work is supported by an EU Horizon 2020 Marie Sklodowska-Curie Action entitled "Classification of forest structural types with LiDAR remote sensing applied to study tree size-density scaling theories" (LORENZLIDAR-658180).

\section{References}

Anderson N, Mitchell D (2016). Forest operations and woody biomass logistics to improve efficiency, value, and sustainability. BioEnergy Research 9: 518-533. - doi: 10.1007/s12155-016-9735-

Asikainen A, Liiri H, Peltola S, Karjalainen T, Laitila J (2008). Forest energy potential in Europe (EU27). Working Papers of the Finnish Forest Research Institute, Finnish Forest Institute, Joensuu, Finland, pp. 1. [online] URL: http://ju kuri.luke.fi/handle/10024/535983

Baltsavias EP (1999). Airborne laser scanning: basic relations and formulas. ISPRS Journal of Photogrammetry and Remote Sensing 54: 199214. - doi: 10.1016/So924-2716(99)00015-5

Bright BC, Hicke JA, Hudak AT (2012). Estimating aboveground carbon stocks of a forest affected by mountain pine beetle in Idaho using LiDAR and multispectral imagery. Remote Sensing of Environment 124: 270-281. - doi: 10.1016/j.rse.2012.05.016

Brosofske KD, Froese RE, Falkowski MJ, Banskota A (2014). A review of methods for mapping and prediction of inventory attributes for operational forest management. Forest Sci- ence 60: 733-756. - doi: 10.5849/forsci.12-134 Chirici G, Mura M, Mclnerney D, Py N, Tomppo EO, Waser LT, Travaglini D, McRoberts RE (2016). A meta-analysis and review of the literature on the k-Nearest Neighbors technique for forestry applications that use remotely sensed data. Remote Sensing of Environment 176: 282294. - doi: 10.1016/j.rse.2016.02.001 Cohen WB, Spies TA (1992). Estimating structural attributes of Douglas-fir Western Hemlock forest stands from Landsat and Spot imagery. Remote Sensing of Environment 41: 1-17. - doi: 10.1016/0034-4257(92)90056-P

Crookston NL, Finley AO (2008). yalmpute: an R package for kNN imputation. Journal of Statistical Software 23: 1-16. - doi: 10.18637/jss.v023. i10

Ediriweera S, Pathirana S, Danaher T, Nichols D (2014). Estimating above-ground biomass by fusion of LiDAR and multispectral data in subtropical woody plant communities in topographically complex terrain in North-eastern Australia. Journal of Forestry Research 25: 761771. - doi: 10.1007/s11676-014-0485-7

García M, Riaño D, Chuvieco E, Danson FM (2010). Estimating biomass carbon stocks for a Mediterranean forest in central Spain using LiDAR height and intensity data. Remote Sensing of Environment 114: 816-830. - doi: 10.1016/j. rse.2009.11.021

González-Olabarria J-R, Rodríguez F, FernándezLanda A, Mola-Yudego B (2012). Mapping fire risk in the Model Forest of Urbión (Spain) based on airborne LiDAR measurements. Forest Ecology and Management 282: 149-156. doi: 10.1016/j.foreco.2012.06.056

Gómez A, Rodrigues M, Montañés C, Dopazo C, Fueyo N (2010). The potential for electricity generation from crop and forestry residues in Spain. Biomass and Bioenergy 34: 703-719. - doi: 10.1016/j.biombioe.2010.01.013

Hauglin M, Dibdiakova J, Gobakken T, Naesset E (2013). Estimating single-tree branch biomass of Norway spruce by airborne laser scanning. ISPRS Journal of Photogrammetry and Remote Sensing 79: 147-156. - doi: 10.1016/j.isprsjprs.20 13.02.013

Heiskanen J, Liu J, Valbuena R, Aynekulu E, Packalén P, Pellikka P (2017). Remote sensing approach for spatial planning of land management interventions in West African savannas. Journal of Arid Environments 140: 29-41. - doi: 10.1016/j.jaridenv.2016.12.006

Hernando A, Arroyo LA, Velazquez J, Tejera R (2012). Objects-based image analysis for mapping Natura 2000 habitats to improve forest management. Photogrammetric Engineering and Remote Sensing 78: 991-999. - doi: 10.1435 8/PERS.78.9.991

Jenkins JC, Chojnacky DC, Heath LS, Birdsey RA (2003). National-scale biomass estimators for United States tree species. Forest Science 49: 12-35. [online] URL: http://academic.oup.com/ forestscience/article/49/1/12/4617214

Kizha AR, Han H-S (2016). Processing and sorting forest residues: cost, productivity and managerial impacts. Biomass and Bioenergy 93: 97-106. doi: 10.1016/j.biombioe.2016.06.021

Kotamaa E, Tokola T, Maltamo M, Packalen P, Kurttila M, Mäkinen A (2010). Integration of remote sensing-based bioenergy inventory data 
and optimal bucking for stand-level decision making. European Journal of Forest Research 129: 875-886. - doi: 10.1007/s10342-010-0357-4 Kristensen T, Ohlson M, Bolstad PV, Kolka R (2015). Mapping above- and below-ground carbon pools in boreal forests: the case for airborne lidar. PLoS ONE 10: e0138450. - doi: 10.1371/journal.pone.0138450

López-Rodríguez F, Perez Atanet C, Cuadros Blazquez F, Ruiz Celma A (2009). Spatial assessment of the bioenergy potential of forest residues in the western province of Spain, Caceres. Biomass and Bioenergy 33: 1358-1366. doi: 10.1016/j.biombioe.2009.05.026

Maltamo M, Naesset E, Vauhkonen J (2014). Forestry applications of airborne laser scanning (Maltamo M, Naesset Vauhkonen J eds). Springer Science and Business Media, Dordrecht, vol. 27, pp. 464. - doi: 10.1007/978-94017-8663-8

Manzanera JA, García-Abril A, Pascual C, Tejera R, Martín-Fernández S, Tokola T, Valbuena R (2016). Fusion of airborne LiDAR and multispectral sensors reveals synergic capabilities in forest structure characterization. GIScience and Remote Sensing 53: 1-16. - doi: 10.1080/1548 1603.2016.1231605

Mauro F, Molina I, García-Abril A, Valbuena R, Ayuga-Téllez E (2016). Remote sensing estimates and measures of uncertainty for forest variables at different aggregation levels. Environmetrics 27 (4): 225-238. - doi: 10.1002/env. 2387

McGaughey RJ (2012). FUSION/LDV: Software for LiDAR data analysis and visualization. Pacific Northwest Research Station, USDA Forest Service, Seattle, Washington, USA. [online] URL: http://forsys.cfr.washington.edu/fusion/fu sionlatest.html

Moeur M, Stage AR (1995). Most similar neighbor - an improved sampling inference procedure for natural-resource planning. Forest Science 41: 337-359. [online] URL: http://acade mic.oup.com/forestscience/article-abstract/41/ 2/337/4626909

Montealegre-Gracia AL, Lamelas-Gracia MT, García-Martín A, De la Riva-Fernández J, EscribanoBernal $F$ (2017). Using low-density discrete Airborne Laser Scanning data to assess the potential carbon dioxide emission in case of a fire event in a Mediterranean pine forest. GIScience and Remote Sensing 23: 1-20. - doi: 10.1080/ 15481603.2017.1320863

Montero G, Ruiz-Peinado R, Muñoz M (2005). Producción de biomasa y fijación de $\mathrm{CO}_{2}$ por los bosques españoles [Biomass production and $\mathrm{CO}_{2}$ fixation for Spanish forests]. Ministerio de Educación y Ciencia, Madrid, Spain, pp. 275. [in Spanish] [online] URL: http://www.researchga te.net/publication/235639682

Mura M, Bottalico F, Giannetti F, Bertani R, Gian- nini R, Mancini $M$, Orlandini S, Travaglini $D$, Chirici G (2018). Exploiting the capabilities of the Sentinel-2 multi spectral instrument for predicting growing stock volume in forest ecosystems. International Journal of Applied Earth Observation and Geoinformation 66: 126-134. doi: 10.1016/j.jag.2017.11.013

Naesset E (2002). Predicting forest stand characteristics with airborne scanning laser using a practical two-stage procedure and field data. Remote Sensing of Environment 80: 88-99. doi: 10.1016/So034-4257(01)00290-5

Naesset E (2004). Estimation of above-and below-ground biomass in boreal forest ecosystems. ISPRS Journal of Photogrammetry and Remote Sensing 36: 145-148. [online] URL: http://www.researchgate.net/publication/31245 8170

Packalén $P$, Suvanto A, Maltamo M (2009). A two stage method to estimate species-specific growing stock. Photogrammetric Engineering and Remote Sensing 75: 1451-1460. - doi: 10.143 58/PERS.75.12.1451

Panichelli L, Gnansounou E (2008). GIS-based approach for defining bioenergy facilities location: a case study in Northern Spain based on marginal delivery costs and resources competition between facilities. Biomass and Bioenergy 32: 289-300. - doi: 10.1016/j.biombioe.2007.10. 008

Patenaude G, Hill RA, Milne R, Gaveau D, Briggs $B$, Dawson TP (2004). Quantifying forest above ground carbon content using LiDAR remote sensing. Remote Sensing of Environment 93: 368-380. - doi: 10.1016/j.rse.2004.07.016

Pineiro G, Perelman S, Guerschman JP, Paruelo JM (2008). How to evaluate models: observed vs. predicted or predicted vs. observed? Ecological Modelling 216: 316-322. - doi: 10.1016/j.eco Imodel.2008.05.006

Popescu SC, Wynne RH, Scrivani JA (2004). Fusion of small-footprint LiDAR and multispectral data to estimate plot-level volume and biomass in deciduous and pine forests in Virginia, USA. Forest Science 50: 551-565. [online] URL: http:// academic.oup.com/forestscience/article/50/4/5 $51 / 4617261$

R Core Team (2011). R: a language and environment for statistical computing. R Core Team, Vienna, Austria. [online] URL: http://www.Rproject.org/

Riaño D, Chuvieco E, Condés S, González-Matesanz J, Ustin SL (2004). Generation of crown bulk density for Pinus sylvestris L. from lidar. Remote Sensing of Environment 92: 345-352. doi: 10.1016/j.rse.2003.12.014

Solberg B, Hetemäki L, Kallio A, Moiseyev A (2014). Impacts of forest bioenergy and policies on the forest sector markets in Europe-what do we know? Technical Reports no. 89, EFI, Joensuu, Finland, pp. 1. [online] URL: http://www.re searchgate.net/publication/260202500

Straub C, Koch B (2011). Enhancement of bioenergy estimations within forests using airborne laser scanning and multispectral line scanner data. Biomass and Bioenergy 35: 3561-3574. doi: 10.1016/j.biombioe.2011.05.017

Valbuena R, Eerikäinen K, Packalén P, Maltamo $M$ (2016). Gini coefficient predictions from airborne LiDAR remote sensing display the effect of management intensity on forest structure. Ecological Indicators 60: 574-585. - doi: 10.1016/ j.ecolind.2015.08.001

Valbuena R, Mauro F, Arjonilla FJ, Manzanera JA (2011). Comparing airborne laser scanning-imagery fusion methods based on geometric accuracy in forested areas. Remote Sensing of Environment 115: 1942-1954. - doi: 10.1016/j.rse.20 11.03.017

Valbuena R, Mauro F, Rodríguez-Solano R, Manzanera JA (2010). Accuracy and precision of GPS receivers under forest canopies in a mountainous environment. Spanish Journal of Agricultural Research 8: 1047. - doi: 10.5424/sjar/20 10084-1242

Valbuena R, Packalén P, Mehtätalo L, GarcíaAbril A, Maltamo M (2013). Characterizing forest structural types and shelterwood dynamics from Lorenz-based indicators predicted by airborne laser scanning. Canadian Journal of Forest Research 43: 1063-1074. - doi: 10.1139/cjfr2013-0147

Valbuena R, Vauhkonen J, Packalén P, Pitkanen J, Maltamo M (2014). Comparison of airborne laser scanning methods for estimating forest structure indicators based on Lorenz curves. ISPRS Journal of Photogrammetry and Remote Sensing 95: 23-33. - doi: 10.1016/j.isprsjprs.20 14.06.002

Verkerk PJ, Anttila P, Eggers J, Lindner M, Asikainen A (2011). The realisable potential supply of woody biomass from forests in the European Union. Forest Ecology and Management 261: 2007-2015. - doi: 10.1016/j.foreco.2011.02.0 27

Verkerk PJ, Levers C, Kuemmerle T, Lindner M, Valbuena R, Verburg PH, Zudin S (2015). Mapping wood production in European forests. Forest Ecology and Management 357: 228-238. doi: 10.1016/j.foreco.2015.08.007

Willmott CJ (1982). Some Comments on the Evaluation of Model Performance. Bulletin of the American Meteorological Society 63: 1309-1313. - doi: 10.1175/1520-0477(1982)063<1309:SCOTE O>2.0.CO;2

Zolkos SG, Goetz SJ, Dubayah RO (2013). A metaanalysis of terrestrial aboveground biomass estimation using LiDAR remote sensing. Remote Sensing of Environment 128: 289-298. - doi: 10.1016/j.rse.2012.10.017 